University of Wollongong

Research Online

Faculty of Social Sciences - Papers (Archive) Faculty of Arts, Social Sciences \& Humanities

2015

The perceptions and experiences of adolescent boys with autism spectrum disorder: a personal construct psychology perspective

Elizabeth Kate Cridland

University of Wollongong, liz_cridland@uow.edu.au

Peter Caputi

University of Wollongong, pcaputi@uow.edu.au

Sandra C. Jones

University of Wollongong, Sandra.Jones@acu.edu.au

Christopher A. Magee

University of Wollongong, cmagee@uow.edu.au

Follow this and additional works at: https://ro.uow.edu.au/sspapers

Part of the Education Commons, and the Social and Behavioral Sciences Commons

Research Online is the open access institutional repository for the University of Wollongong. For further information contact the UOW Library: research-pubs@uow.edu.au 


\title{
The perceptions and experiences of adolescent boys with autism spectrum disorder: a personal construct psychology perspective
}

\author{
Abstract \\ Background This study applies personal construct psychology for understanding the experiences of \\ adolescents with autism spectrum disorder (ASD). Method Semistructured interviews were conducted \\ with 26 participants from 8 families, including adolescent males with ASD, mothers, fathers, and \\ adolescent neurotypically developing siblings. Analysis of interview data was structured according to the \\ themes presented in a previous theoretical application of personal construct theory (PCT) for \\ understanding adolescents with ASD. Results Themes included complexity of the adolescent social \\ realm, sense-making in multifaceted situations, identity development, development of flexible processing \\ styles, and understanding and managing physical and emotional changes associated with puberty. \\ Conclusion The study provides empirical support for the application of PCT for understanding \\ adolescents with ASD. The insights provided by the participants may be helpful for adolescents with ASD, \\ family members, and clinicians.

\section{Keywords} \\ perspective, spectrum, psychology, autism, boys, adolescent, experiences, perceptions, construct, \\ personal, disorder

\section{Disciplines} \\ Education | Social and Behavioral Sciences

\section{Publication Details} \\ Cridland, E. K., Caputi, P., Jones, S. C. \& Magee, C. A. (2015). The perceptions and experiences of \\ adolescent boys with autism spectrum disorder: a personal construct psychology perspective. Journal of \\ Intellectual and Developmental Disability, 40 (4), 354-367.
}




\title{
The perceptions and experiences of adolescent boys with autism spectrum disorder: A personal construct psychology perspective
}

\author{
ELIZABETH K. CRIDLAND ${ }^{1,2}$, PETER CAPUTI ${ }^{1,2}$, SANDRA C. JONES ${ }^{2}$ \& \\ CHRISTOPHER A. MAGEE ${ }^{2}$ \\ ${ }^{1}$ School of Psychology, University of Wollongong, Wollongong, Australia, and ${ }^{2}$ Centre for Health Initiatives, University of \\ Wollongong, Wollongong, Australia
}

\begin{abstract}
Background This study applies personal construct psychology for understanding the experiences of adolescents with autism spectrum disorder (ASD).

Method Semistructured interviews were conducted with 26 participants from 8 families, including adolescent males with ASD, mothers, fathers, and adolescent neurotypically developing siblings. Analysis of interview data was structured according to the themes presented in a previous theoretical application of personal construct theory (PCT) for understanding adolescents with ASD.

Results Themes included complexity of the adolescent social realm, sense-making in multifaceted situations, identity development, development of flexible processing styles, and understanding and managing physical and emotional changes associated with puberty.

Conclusion The study provides empirical support for the application of PCT for understanding adolescents with ASD. The insights provided by the participants may be helpful for adolescents with ASD, family members, and clinicians.
\end{abstract}

Keywords: autism spectrum disorder, high-functioning ASD, adolescence, puberty, identity development, personal construct theory, high school

Introduction

Adolescent development involves a range of physical, social, emotional, and cognitive changes (Levesque, 2011). Transitioning to secondary school is another significant change for adolescents involving management of complex routines, increased student population, increased academic workload and expectations, more varied and complex subjects and assignments, and exposure to a greater number of teachers (Adreon \& Stella, 2001; Carrington \& Graham, 2001; Poon et al., 2014). Adjusting to these broad-ranging changes can result in vulnerability to stress, anxiety, and other emotional issues for many adolescents (Myles \& Simpson, 2003).

A subgroup of adolescents reported to be particularly vulnerable to the negative effects of these developmental changes are those with autism spectrum disorder (ASD; Barnhill \& Myles, 2001; Lasgaard, Nielsen, Eriksen, \& Goossens, 2010; White \& Roberson-Nay, 2009). Individuals with ASD experience persistent and significant social communicative impairments, as well as restricted and repetitive behaviours and/or interests (American Psychiatric Association [APA], 2013). Although several studies report that some individuals with ASD experience improvements during adolescence (in areas such as communication, social interaction, restrictive and repetitive behaviours, and daily living skills; McGovern \& Sigman, 2005; Smith, Maenner, \& Seltzer, 2012), other research indicates that many adolescents with ASD experience symptom deterioration in areas such as frequency and intensity of sensory abnormalities, compulsions, self-injurious behaviour and aggression, cognitive rigidity, and inappropriate 
sexualised behaviour (Kring, Greenberg, \& Seltzer, 2009; Levy \& Perry, 2011; Seltzer, Shattuck, Abbeduto, \& Greenberg, 2004). For this reason, understanding the experience of adolescence for individuals with ASD is of high importance for the individuals themselves, their families, and clinicians (Levy \& Perry, 2011).

Personal construct theory

In this study, we apply personal construct psychology (Kelly, 1955, 2003) for understanding the experiences of adolescents with ASD. Personal construct theory (PCT) is a constructivist approach to understanding human thought and action, derived from the clinical and theoretical work of George Kelly (1955). PCT is grounded in the assumption that individuals construct a subjective model of their world based on reality (Kelly, 1955, 2003). Referred to as "personal constructs," these individualised models of reality guide the way people process and interpret their world. Personal constructions are considered to develop over time from both direct and anticipated experiences and interactions (Kelly, 1955, 2003). Moreover, a personal constructivist framework posits that individuals develop hierarchically organised networks of constructs. Such hierarchical organisation of constructions allows us to interpret, understand, and anticipate situations more easily than if each situation was interpreted by its various, individual (lower-order or subordinate) constructs.

As construct systems are developed from personal experiences, there are diverse ways in which people can construe the world (Kelly, 1955). Coupled with this perspective, however, is recognition that people with mutual experiences, such as members of a family, often develop some shared constructs (Procter, 2001). Constructive alternativism also recognises that individuals have the capacity to change their constructions through reconstruing processes. This capacity to change ways of viewing the world promotes an optimistic outlook for individuals who hold ineffective or maladaptive constructions and is the basis of PCT grounded therapy (Badzinski \& Anderson, 2012). The benefits of utilising a PCT framework with this population include eloquent explanations about the construing processes of individuals with ASD (Cridland, Caputi, Jones, \& Magee, 2014; Procter, 2001). From this, understanding the experiences of adolescents with ASD within a personal constructivist framework may be helpful for family members and clinicians to recognise that adolescents with ASD may differ in their constructions of their world, themselves, and others (Cridland, Caputi, et al., 2014; Truneckova \& Viney, 2012). Further, it may facilitate sensitivity to the possible ways in which these constructions may affect individuals' mental health and wellbeing (Cridland, Caputi, et al., 2014).

The application of PCT for understanding the experiences of adolescents with ASD was previously outlined by Cridland, Caputi, et al. (2014). In the aforementioned paper, the authors considered various adolescent development tasks using a PCT framework, including functioning within the increasingly complex world of adulthood, sense-making in complex situations, identity development, and development of flexible processing styles. Cridland, Caputi, et al. (2014) discussed the advantages of understanding adolescents with ASD through the lens of PCT; however, the authors also highlighted the need for empirical research to validate the application of PCT to this subgroup of individuals. The present study aims to address this recommendation and extend on the areas to which PCT was theoretically applied.

\section{Aims}

The overarching aim of this study was to understand the perceptions and experiences of adolescents with ASD from a personal construct psychology perspective. Qualitative data collection methods and analyses were used to gain detailed perspectives of the lived experiences of adolescents with ASD and their families.

Based on existing literature and the first author's clinical experience, it was hypothesised that the issues highlighted in a previous application of PCT for understanding adolescents with ASD (see Table 2) would be relevant to the issues discussed by adolescents with ASD and their families. The nature of additional issues raised by participants pertinent to their experience of being an adolescent/having an adolescent family member with ASD was unknown.

\section{Method \\ Sample}

The sample consisted of 26 participants from eight families. Specifically, the sample included mothers $(\mathrm{n}=8)$, fathers $(\mathrm{n}=7)$, adolescent neurotypically developing (NTD) siblings $(n=4)$, and adolescents with $\operatorname{ASD}^{1}(n=7)$. Eligibility criteria for the families included having two parents who identify as the primary caregivers with at least two adolescent children (one NTD individual ${ }^{2}$ and one son with $\mathrm{ASD}^{3}$ ); all family members living at home a minimum of 5 days per week; only one family member formally diagnosed with an ASD; and all 
Table 1. Participant demographic information

\begin{tabular}{|c|c|c|c|c|c|c|c|c|}
\hline \multirow{2}{*}{$\begin{array}{l}\text { Family } \\
\text { identifier }\end{array}$} & \multicolumn{4}{|c|}{ Participating family members } & \multirow{2}{*}{$\begin{array}{l}\text { Adolescent } \\
\text { age }\end{array}$} & \multirow[b]{2}{*}{ Adolescent school level } & \multirow{2}{*}{$\begin{array}{c}\text { Sibling } \\
\text { gender (age) }\end{array}$} & \multirow{2}{*}{$\begin{array}{l}\text { Estimated annual } \\
\text { household income }\end{array}$} \\
\hline & Mother & Father & Adolescent & Sibling & & & & \\
\hline Family 1 & Yes & Yes & Yes & Yes & 13 & $\begin{array}{l}\text { Year } 8 \text { mainstream } \\
\text { school }\end{array}$ & Female (12) & $\$ 80,000$ \\
\hline Family 2 & Yes & Yes & Yes & Yes & 14 & $\begin{array}{l}\text { Year } 8 \text { mainstream } \\
\text { school }\end{array}$ & Male (17) & $>\$ 100,000$ \\
\hline Family 3 & Yes & Yes & Yes & No & 16 & $\begin{array}{l}\text { Year } 10 \text { mainstream } \\
\text { school }\end{array}$ & Male (18) & $\$ 80,000$ \\
\hline Family 4 & Yes & No & Yes & Yes & 13 & $\begin{array}{l}\text { Year } 7 \text { mainstream } \\
\text { school with ASD unit }\end{array}$ & Female (16) & $\$ 40,000$ \\
\hline Family 5 & Yes & Yes & Yes & Yes & 15 & $\begin{array}{l}\text { Year } 9 \text { mainstream } \\
\text { school with ASD unit }\end{array}$ & Female (17) & $\$ 60,000$ \\
\hline Family 6 & Yes & Yes & Yes & No & 12 & $\begin{array}{l}\text { Year } 7 \text { mainstream } \\
\text { school }\end{array}$ & Female (1t) & \\
\hline Family 7 & Yes & Yes & Yes & No & 15 & $\begin{array}{l}\text { Year } 9 \text { mainstream } \\
\text { school }\end{array}$ & Male (19) & $\$ 90,000$ \\
\hline Family 8 & Yes & Yes & No & No & 14 & $\begin{array}{l}\text { Year } 8 \text { mainstream } \\
\text { school }\end{array}$ & Female (16) & $\$ 50,000$ \\
\hline
\end{tabular}

family members having knowledge of the ASD diagnosis. Additional sample demographic information is presented in Table 1 . The rationale for focusing on adolescent males with ASD was based on the current predominance of males diagnosed with ASD (Holtmann, Bölte, \& Poustka, 2007; Krahn \& Fenton, 2012) and previous recommendations to acknowledge the influence of gender on research findings (Card, Stucky, Sawalani, \& Little, 2008; Cridland, Jones, Caputi, \& Magee, 2014; Hsiao, Tseng, Huang, \& Gau, 2013).

Procedure

Ethical approval was granted by the University of Wollongong's Human Research Ethics Committee prior to commencing the participant recruitment process. Research aims were explained in a participant information sheet and an introductory meeting with the first author. Following ethical standards for research with children, written consent was obtained from the participants and their parents.

An interview guide was developed based on a review of relevant interview guides (Benderix \& Sivberg, 2007; Carrington \& Graham, 2001; Mascha \& Boucher, 2006; Vliem, 2009) and through multiple discussions among the research team. Based on research recommendations (Cridland, Jones, Caputi, \& Magee, 2015), the interview guide was pilot tested on one family with an adolescent family member with ASD. Minor wording changes to questions resulted from pilot testing.

Interview questions were generally related to experiences of being an adolescent/having a family

Table 2. Thematic codes

\begin{tabular}{|c|c|}
\hline Themes presented in Cridland, Caputi, et al., 2014 & Themes and subthemes presented in the current investigation \\
\hline Increasing complexity of the social realm & $\begin{array}{l}\text { Increasing complexity of the adolescent social realm } \\
\text {. Developing and maintaining friendships } \\
\text {. Interacting with girls } \\
\text {. Experiences of bullying } \\
\text {. Limited social opportunities with peers }\end{array}$ \\
\hline Sense-making in complex social situations & $\begin{array}{l}\text { Sense-making in complex social situations } \\
\text {. Processing and functioning within multifaceted situations } \\
\text {. Ability to focus } \\
\text { Unique perception of the world }\end{array}$ \\
\hline Identity development & $\begin{array}{l}\text { Identity development } \\
\text {. Self-description } \\
\text {. Impact of ASD on identity }\end{array}$ \\
\hline Developing flexible processing styles & $\begin{array}{l}\text { Developing flexible processing styles } \\
\text { Challenges of puberty } \\
\text {. Understanding and managing physical changes } \\
\text {. Understanding and managing emotions }\end{array}$ \\
\hline
\end{tabular}


member with ASD. There was scope for flexibility in topics discussed as well as follow-up questions to encourage elaboration. A copy of the interview guide is available from the corresponding author.

Interviews were conducted based on recommendations outlined in Cridland et al. (2015), including conducting interviews with individual participants in a private space within the family home (e.g., study or quiet living area); conducting interviews at a preferred time for participants; and conducting interviews at an appropriate pace to facilitate accurate interpretation of interview questions. Interviews lasted for an average of approximately 60 minutes (range: 40-150 minutes). Interviews were audiorecorded for transcription.

\section{Data analysis}

NVivo Version 10 (QSR International, 2012), a qualitative data management program, was used to manage and analyse the data. Data were initially coded based on the themes discussed in Cridland, Caputi, et al. (2014), with additional themes generated from the remaining data. A formal measure of interrater agreement was not employed. Rather, the process involved one of the co-authors and one independent checker reading all transcripts with the potential themes identified by the first author. No major changes to the themes identified by the first author were identified as being necessary by either check. Following the analysis procedure outlined by Braun and Clarke (2006), a final consultation with the authors followed to discuss specific theme descriptions and selection of the most relevant quotes.

\section{Results}

The themes and subthemes presented in the current investigation are set out in Table 2. Specifically, the first four themes are based on themes presented in Cridland, Caputi, et al. (2014), with one additional theme, describing the challenges of puberty, emerging from the remaining data.

Increasing complexity of the adolescent social realm

Developing and maintaining friendships. All participants $(n=26 / 26)$ described the difficulties that they or their family member experienced developing and maintaining friendships during adolescence. Reasons for these difficulties included trouble understanding the perspectives of others, difficulty conversing effectively, and challenges understanding the more subtle and complex functioning of adolescent relationships:

Their brain is different so they have to learn how to read other people's emotions... I can't read other people ... (Adolescent, Family 1$)^{4}$
... he finds it hard to mix with kids who don't have ASD ... And now that he's a teenager he has less friends than in primary. ... I think the friendships just become more complicated. (Mother, Family 3)

Difficulty discerning between acquaintances and close friendships was another challenge for the adolescents. More specifically, although the majority of adolescents $(n=6 / 7)$ described having close friends and/or being part of a friendship group, the majority of family members $(n=15 / 19)$ considered these relationships to be acquaintances rather than close friendships. Interviews indicated that the adolescents' awareness about these relationship differences ranged from ignorance to a desire to form closer connections with their peers:

At school I generally hang around with my mates ... We always joke around ... [we] play soccer on the field and sometimes talk ... (Adolescent, Family 2) ... if you ask him if he has friends he will say yes but ... he doesn't actually interact with them, he just watches them from the sidelines ... he thinks that is friendship. (Mother, Family 7)

Interacting with girls. Some participants discussed the challenges faced by the adolescents regarding interacting with adolescent girls. Such issues included feeling uncomfortable talking with girls and uncertainty regarding the concept of a "girlfriend:"

He doesn't mix with girls, like when he's around girls he kind of just gets a bit bashful and steps back a bit ... I think he's interested... But only with the girls that are like him, not the other girls in his grade.

(Sister, Family 5)

Experiences of bullying. At least one participant from each family described experiences where their family member with ASD had been bullied as an adolescent. Various reasons for the bullying were discussed, including the adolescent's limited tolerance for NTD adolescent behaviour, naivety, and/or social awkwardness:

... he was getting bullied by this one guy ... [who] was saying to him, "Give me $\$ 10$ and Ill give you an iPhone" and my brother would believe it and would give him the money and wouldn't get anything from 
it ... he just doesn't understand that they are lying ... I think it makes him feel vulnerable. (Sister, Family 4)

Limited social opportunities with peers. The majority of participants ( $n=17 / 26)$ made reference to the adolescents limited involvement in social outings. These comments were generally made in comparison to the siblings' social patterns. Reasons for the limited social outings included minimal invitations from peers, social anxieties, and difficulties managing social events:

[NTD teenagers] get out more and do stuff... [I don't go out much but] it's not that I don't want to do it; it's that they don't want me to... [Also] I don't like getting out that much but I want to. (Adolescent, Family 4)

I can't remember the last time he went to a birthday and that was the sort of thing I was doing at his age

... (Brother, Family 2)

A lot of kids don't want to play with him and they don't invite him to birthday parties and they don't invite him over to their place because with the behavioural issues it just turns them off. (Father, Family 6)

Sense-making in complex social situations

Processing and functioning within multifaceted situations. Family members discussed various challenges the adolescents faced when processing and functioning within multifaceted situations. Some of these challenges included processing multiple instructions, planning steps necessary to complete an activity, and simultaneous processing of sensory information and body movements to engage in daily activities such as sports or cooking:

You can't give him directions; if you give him more than two things in an instruction to do, he gets confused ... [Also] he really struggles with school, it's all too much of a sensory onslaught for him; ... the bells go and kids are running everywhere ... [or when the teacher is] standing in front of the classroom talking, he just gets information overload and he just can't absorb it... [Also] he can't play sport... everyone gets angry at him because he can't kick the ball and they get frustrated at him ... (Mother, Family 7)

Ability to focus. Many family members $(n=14 / 19)$ discussed the adolescents' ability to intensely focus on topics of interest. The ability to focus on topics of interest was contrasted with general focusing ability, which was considered to be comparatively poor:

Some people [with ASD] are focused on one thing ...

I like to play computer games and board games. They are my main hobbies and favourite things to do. (Adolescent, Family 1)

When he gets into something, he really gets into it. Like if were talking about a book that we have both read he will remember it in immense detail... I admire that, I really like it. [But it's] so funny because he never remembers where his lunch box is or his socks! (Mother, Family 1)

The ability to focus intensely also resulted in strong memory skills for topics of interest. In particular, some family members $(n=12 / 19)$ commented on the adolescents' ability to remember detailed information:

I like the way he can read a book and remember lots of information out of it without even really thinking about it... he might not be able to concentrate on his school work but when he is doing different things like that, like even watching the History Channel he can concentrate fully and take it all in. (Father, Family 7)

Unique perception of the world. The adolescents' way of making sense of complex situations often resulted in a unique way of perceiving the world. In particular, some family members $(n=9 / 19)$ discussed their adolescent's ability to observe the world in its simplicity:

His understanding of the world is brilliant ... He has this ability to boil it down to the essence ... he will say something really, really profound and it changes the way you see the world. He is just amazing. (Mother, Family 2)

Identity development

Self-description. In order to investigate personality development, the adolescents were asked to describe themselves. The majority of adolescents $(n=6 / 7)$ were able to provide self-descriptors to varying extents, despite the fact that some were only able to provide minimal elaboration and/or focused on activities they liked rather than personality characteristics. Some self-descriptions described core characteristics of ASD, such as difficulty connecting with people:

I can be dogged ... [and] it takes me a while to connect with people and I read books a lot. (Adolescent, Family 1)

I don't even know if I even have a personality ... I'm not very describable ... (Adolescent, Family 3) 
I don't really know if I can describe myself because ... That is difficult ... [I am a] a smart person and quiet person ... those are actually two traits of my personality ... [Another] would be the things I do, like most of the time I'm typing away on my lap top ... (Adolescent, Family 5)

Difficulties describing identity/personality characteristics were echoed by some family members $(n=3 / 19)$ :

I imagine he might have trouble describing himself. He loves gaming and stuff so whether he would take that as part of [his identity]? He might say that he is friendly in his own little way... I don't really know (Mother, Family 7).

When family members were asked to describe their adolescents' identity/personality, various participants described ways in which it had developed over time. The predominant personality characteristics developing into adolescence included self-confidence, social skills, affectionate nature, and sense of humour.

He's just lovely. He's a bit of a joker, which came with age. He hated dressing up and pretend-play, he hated that as a little boy but he sort of grew into jokes and stuff. (Mother, Family 5)

He is really affectionate and has remained more affectionate at an older age than Rick [my NTD son] did. (Mother, Family 2)

Impact of ASD on identity. The majority of adolescents ( $n=4 / 7$ ) conveyed uncertainty around the ways ASD impacted their identity and/or stated that ASD had no impact on their sense of self:

It's okay that I have AS, otherwise I wouldn't be who I am ... It doesn't really affect me ... You are born with AS so I have always had it and have never had a problem with it... I mean it's a brain thing so that is going to make you different, but I don't know what ways. (Adolescent, Family 1)

I don't really know what AS does [to me] ... It's not a good thing or a bad thing, it's just a thing! ... (Adolescent, Family 7)

The other adolescents $(n=3 / 7)$ reflected that having ASD influenced them in both positive and negative ways. The main positive aspect of having ASD they identified was feeling special or unique. Negative aspects of having ASD included feeling different and/or misunderstood, and having social difficulties:

I actually really like having this disability because it actually makes me feel a bit special ... [but] everyone with AS feels frustrated when people do not understand them ... (Adolescent, Family 5)

Sometimes it's like I'm an alien ... [but] at least I've got something in my life that happens, like at least I've got something positive in my life that will stick with me forever. (Adolescent, Family 4)

I don't mind [having ASD] but I just wish I was more social ... [It would feel] nice for someone to at least comprehend the problems I go through every day.

(Adolescent, Family 2)

Developing flexible processing styles

The majority of family members $(n=15 / 19)$ discussed the adolescents' tendency to have rigid thought processing styles rather than developing flexible processing. Common areas of rigidity included retaining an opinion despite conflicting evidence, following rules without exception, difficulty accommodating change, and perfectionism:

He gets very fixed on an idea. It can be very frustrating at times but it can be good at other times... If he has an idea on something ... he will stick to that even if you tell him it is wrong ... (Brother, Family 2)

[He] thinks he is right all of the time and that is his downfall ... sort of contradicts everything you say. He's a real challenger; he will challenge you on everything. (Father, Family 6)

Challenges of puberty

Understanding and managing physical changes. Family members described various attitudes exhibited by their family member with ASD regard- ing the physical changes they were experiencing associated with adolescence. These attitudes ranged from disgust to confusion to a logical and mature outlook:

[He didn't like] being at school for sex education and personal development and things like that. He was horrified ... he was just like, "Oh my God! This is gross." (Mother, Family 8)

Curtis didn't have many questions [about puberty] ... he knows all the factual stuff but I don't know if he knows the romantic side of it all. They all are mature like that... it's all just a body thing... He didn't particularly get embarrassed. (Mother, Family 3)

Difficulty managing the bodily changes associated with puberty was discussed by the majority of family members $(n=14 / 19)$. Areas of difficulty included adjusting to the heightened hygiene routines of adolescence, and understanding appropriate versus inappropriate public behaviours: 
He also doesn't always realise when his feet and armpits smell. He doesn't pick up on the social things with that. (Mother, Family 1)

Hell just strip off wherever! ... And now that he has hit puberty it has gotten worse ... I just constantly tell him that he is developing now and he can't do it anymore because he is not a little kid. But he keeps doing it! It's scary sometimes. (Mother, Family 8)

Understanding and managing emotions. All but one family member $(n=18 / 19)$ discussed the challenges experienced by adolescents regarding understanding emotions. In particular, participants described the adolescent's difficulty understanding degrees of negative emotion expressed by others:

He gets very moody and thinks I'm cranky at him whenever I say "No"... He just doesn't understand that sometimes I have to say no and I'm not doing it to be angry or mean, but it's for a reason. (Mother, Family 4)

Management of emotions was considered a challenge for adolescents by all family members who discussed this issue. These participants indicated the most challenging emotion to be managed was anger. More specifically, it was identified that the adolescents struggled with controlling their emotions, and sometimes expressed their emotions in a socially inappropriate way:

I get angry easy ... A lot of things [make me angry], probably people saying stuff about me ... like, "Aw look at that retarded kid"... I usually just swear at them and sometimes hit them... I know it's bad. (Adolescent, Family 6)

His anger is a big part of his challenges ... He waits until he gets home, like into a safe environment where he knows he can "go-off" ... [He has] trouble controlling his emotions and what's going on for him inside... Hell get violent if any of us is in his way or trying to help and he doesn't want it... (Sister, Family 4)

\section{Discussion}

This study applied PCT for understanding the experiences of adolescents with ASD. Analysis of interview data was structured according to themes presented in a previous theoretical application of PCT for understanding adolescents with ASD (Cridland, Caputi, et al., 2014). Further reflection of the themes based on a PCT perspective and the general research literature is presented as follows.

Increasing complexity of the adolescent social realm

Family member interviews indicated that all adoles- cents had experienced significant difficulties developing and maintaining friendships with their NTD peers. Such difficulties included confusion differentiating between friends and acquaintances, difficulties interacting with girls, experiences of bullying, and having limited social outings with peers. Many of these difficulties were related to the core social deficits inherent to ASD, such as difficulties with perspective taking and conversing with others, and/or were compounded by the increasing complexity of adolescent relationships. Importantly, some of the perceptions expressed by the adolescents differed from those of their family members. For example, the majority of adolescents reported having close friends and/or being part of a friendship group, whereas the majority of family members disagreed. This disparity may reflect an underestimation of friendship quality by family members or may reflect the adolescents' misunderstanding of social interactions.

These findings that adolescents had difficulties interacting with NTD peers are in line with research that indicates that many adolescents with ASD experience social difficulties given the increasing complexity of adolescent relationships, coupled with the heightened societal expectations of functioning that occur during adolescence (Adreon \& Stella, 2001; Carrington, Templeton, \& Papinczak, 2003; Howard, Cohn, \& Orsmond, 2006; White \& Roberson-Nay, 2009). These findings also support a PCT perspective, in which adolescents with ASD find complex social situations challenging, and thus anxiety provoking, if they do not have well-developed constructs about the social situation (Cridland, Caputi, et al., 2014; Kelly, 1955; McCoy, 1977). A PCT perspective also posits that adolescents with ASD have difficulty understanding that other people's constructs about the world may differ from their own (i.e., theory of mind deficit), which can compound their social difficulties (Cridland, Caputi, et al., 2014).

The social isolation reported by the majority of adolescents, resulting from difficulty developing and maintaining friendships, has also been echoed in the literature. For example, Müller et al. (2008) found adults with ASD reported that intense and chronic isolation was a defining feature of their experience of ASD, despite their longing for social connectedness. Similarly, a diary study tracking how adolescents with ASD spent their free time indicated that these individuals spend relatively more time engaged in solitary activities compared to their 
NTD peers due to the unavailability of others' company rather than by choice (Orsmond \& Kuo, 2011). The present findings, along with existing research, indicate that adolescents with ASD have a strong desire for meaningful peer relationships and enjoy positive social interactions with peers, but often have difficulty successfully achieving this (Bauminger, Shulman, \& Agam, 2003; Howard et al., 2006; Lasgaard et al., 2010; McGuire, 2009; Müller et al., 2008; Orsmond \& Kuo, 2011). This suggests it would be important for families and clinicians to facilitate organisation of social activities for adolescents with ASD.

Peer relationships are of increased importance during adolescence and protective against mental health issues such as depression and anxiety (Pinkerton \& Dolan, 2007; Schuntermann, 2007). Conversely, difficulties experienced with peer relationships, and the social isolation often associated with this, can contribute to and/or exacerbate mental health problems (Barnhill \& Myles, 2001; Koning \& Magill-Evans, 2001; Müller et al., 2008). Given the difficulties adolescents with ASD have in developing and maintaining friendships, they are particularly vulnerable to experiencing emotional problems. For example, research indicates that levels of comorbid mental health issues in adolescents with ASD may be as high as $81 \%$ (Barnhill \& Myles, 2001; Lasgaard et al., 2010; Levy \& Perry, 2011; White \& Roberson-Nay, 2009).

Sense-making in complex social situations

The adolescents in this study experienced various challenges processing and functioning within multifaceted situations. Such challenges included difficulties processing instructions and planning steps needed to enable them to undertake everyday activities, and difficulty coordinating bodily movements with sensory input needed for tasks typically expected of adolescents. Importantly, the reporting of these difficulties was from family members rather than the adolescents themselves. This may indicate that the adolescents did not perceive they had difficulty interpreting complex situations. Alternatively, the adolescents may have found it challenging to express these difficulties and therefore chose not to discuss these issues. Another reason why they may not have discussed difficulties making sense of complex social situations is that they were not explicitly asked about such issues.

Utilising a personal constructivist position, these difficulties can be attributed to the processing style of adolescents with ASD. That is, adolescents with ASD may underutilise hierarchically organised construct systems leading to construct systems dominated by isolated, subordinate constructs that require "manual" interpretation of the numerous "separate" components of the situation (Cridland, Caputi, et al., 2014). The drawback of such processing is that the "big picture" of a situation may not be realised, thus increasing opportunity for misinterpretation and placing greater cognitive demand on the individual. This processing style, coupled with underdeveloped abstract thinking skills, accounts for the difficulties adolescents with ASD experience making sense of complex situations.

Discussion of the adolescents' ability to focus and remember immense detail about topics of interest, and comparatively poor ability to focus on other everyday tasks, can be taken as evidence for their underutilisation of hierarchically organised constructs. Additionally, discussion about the adolescents' unique way of perceiving the world, especially in regard to their ability to "boil a situation down to its essence," may be considered evidence of a "subordinate processing" style. Although some participants recognised positive aspects of this style of processing (e.g., ability to focus, memory for detail, unique perception of the world), drawbacks were also acknowledged (i.e., difficulty processing complex situations, poor general memory, and difficulty focusing on meaningful aspects of a situation).

Identity development

Identity development, or forming a sense of self, is a central component of adolescence (Artar, 2007). According to PCT, a person forms a sense of identity with the development of highly complex constructs, referred to as core constructs (Butler, 2006; Kelly, 1955). Given the reliance of individuals with ASD on subordinate constructs, it has been theorised that adolescents with ASD may experience a poorly developed sense of identity (Cottenceau et al., 2012; Cridland, Caputi, et al., 2014; Procter, 2001).

Additionally, identity development is considered a largely social process as it involves interpretation of implicit and explicit feedback from others (Artar, 2007; Butler, 2006; Rowe, 2003; Walker, 1996; Willey, 2003; Ybrandt, 2008), which adolescents with ASD typically find difficult. Together, these factors have resulted in the prediction that adolescents with ASD will have difficulty developing a sense of identity (Cottenceau et al., 2012; Cridland, Caputi, et al., 2014; Procter, 2001).

The results of the current investigation both substantiate and contradict the hypothesis that adolescents with ASD have a poorly developed sense of identity. First, the majority of adolescents showed evidence of a developing sense of self, as they were 
able to provide self-descriptions. However, some adolescents provided basic self-descriptions and/or described their hobbies or interests rather than their identity as such. Further, several family members predicted that the adolescents would have difficulty describing themselves. Together, these findings suggest that some adolescents with ASD may experience difficulty developing a sense of identity.

Regarding the social process of identity development, some comments from the adolescents indicated reflection on feedback from others (e.g., "Some people say I don't look people in the eyes when I talk ..."). However, it remains unclear the extent to which this feedback impacted on their sense of self. The nature of identity development in adolescents with ASD needs to be further investigated (Cridland, Caputi, et al., 2014; Pakenham, Sofronoff, \& Samios, 2004).

The adolescents were also asked to discuss the impact of ASD on their identity. The majority of adolescents were unaware or unsure of the influence of ASD on their sense of self. However, some described core characteristics of ASD in their self-descriptions (e.g., difficulty connecting with people), as did various various family members (e.g., genuine and affectionate nature, and resistant to change). Denial that ASD had any impact on their identity may also be associated with uncertainty about the nature of ASD itself.

Among those adolescents who did acknowledge ASD's impact, both positive and negative impacts were discussed. This finding is consistent with previous research that found that adolescents with ASD described both positive and negative aspects of their condition, with many expressing both views (Poon et al., 2014). Common to both the positive and negative influences of ASD was a sense of feeling different, with some adolescents construing this as being unique or special, and others construing this as feeling isolated and misunderstood. The adolescents' sense of feeling "different" is echoed in the literature, as research indicates that adolescents with ASD can become increasingly aware of their social difficulties, their trouble "fitting in," and their general distinction from peers (Fullerton \& Coyne, 1999; Stoddart, 1999). Such awareness has been associated with mental health issues, including depression and anxiety, and externalising behaviour, including aggression (Barnhill \& Myles, 2001; Levesque, 2011; Myles \& Simpson, 2003).

Developing flexible processing styles

The current findings indicated that the majority of adolescents utilised rigid thought-processing styles rather than more flexible processing. Common areas of rigidity included retaining an opinion despite conflicting evidence, following rules without exception, difficulty accommodating change, and perfectionism. As with sense-making of complex situ- ations, the difficulties experienced by the adolescents were reported by family members rather than the adolescents themselves. Reasons for this lack of discussion may include minimal awareness of their rigid processing styles, difficulty expressing their challenges with flexible processing, and/or may be reflective of the interview guide, which did not ask directly about processing styles.

From a PCT perspective, rigid thought-processing styles inhibit reflection, revision, and elaboration of personal constructs (Kelly, 1955). During adolescence, inflexible processing may be particularly ineffective given the increased variety of new and complex situations individuals are exposed to, such as high school, and the physical and emotional changes associated with puberty (Cridland, Caputi, et al., 2014). Along with increasingly complex social interactions and expectations for functioning, adolescents with ASD are vulnerable to finding everyday situations challenging. This was evident throughout the interviews. Understanding the reasons why adolescents with ASD have rigid processing styles, within a PCT framework, may foster more empathetic and understanding attitudes.

Comorbid mental health issues can also influence the cognitive functioning of adolescents with ASD. Research indicates areas of particular vulnerability include cognitive flexibility, perspective taking, and abstract thinking (Barnhill \& Myles, 2001). Given the susceptibility of adolescents with ASD to mental health issues, and their cognitive processing styles, their experience of adolescence as challenging comes as no surprise.

\section{Challenges of puberty}

Participants described a range of physical and emotional changes experienced by the adolescents. These changes may be considered common to all adolescents (e.g., growth spurts, sexual development, need for increased hygiene routines, emotional sensitivity, management of strong emotions; Levesque, 2011), but of particular interest here was the adolescents' understanding and management of the changes. The adolescents' perceptions about puberty varied from confusion to disgust to a mature level of understanding. Regarding management of pubescent changes, responses ranged from ignorance to curiosity to feeling overwhelmed. 
From a PCT perspective, the varying perceptions about puberty may be reflective of the individuals' different construct systems, with negative perceptions reflective of negative constructions about pubertal changes. Alternatively, the differing perceptions may be understood as a reflection of differing degrees of construct elaboration. That is, individuals with well-developed constructs about pubertal changes may be more likely to have a mature response to adolescent development as opposed to those with poorly developed constructs about puberty. For parents and clinicians, this means that adolescents with ASD may adjust more easily to developmental changes with greater knowledge about puberty.

Many family members discussed their adolescent family members' difficulties in recognising degrees of emotion, especially anger, expressed by others as a key challenge during this period. Interestingly, none of the adolescents discussed this reported difficulty as a challenge for them, which may indicate their minimal awareness of their troubles identifying negative emotions. Research in this area supports these findings, as it indicates that individuals with ASD process negative facial expressions differently, and less efficiently, than NTD controls (Farran, Branson, \& King, 2011; Isomura, Ogawa, Yamada, Shibasaki, \& Masataka, 2014; Pelphrey et al., 2002). Such processing differences have been understood to reflect the deficits in facial affect recognition, particularly of negative expressions, evident in some individuals with ASD (Farran et al., 2011; Pelphrey et al., 2002). According to a personal constructivist interpretation, the differing processing styles of NTD individuals and individuals with ASD can be attributed to the organisation of personal constructs, as discussed previously.

In addition to difficulties identifying and understanding emotions expressed by others, participants discussed the adolescents' difficulties managing their experiences of anger. Although not inherent to the condition, anger is a clinically significant issue for many individuals with ASD and their families, with research indicating it is particularly problematic for adolescent males with ASD (Hodgetts, Nicholas, \& Zwaigenbaum, 2013; Kanne \& Mazurek, 2011; Mazurek, Kanne, \& Wodka, 2013). For example, two large-scale studies investigating the experiences of anger in children and adolescents with ASD have found that over half display significant physical aggression (Kanne \& Mazurek, 2011; Mazurek et al., 2013). Although the predictors of anger in individuals with ASD are not well understood, it has been suggested that it may stem from the frustration of feeling different and isolated from their peers (Barnhill \& Myles, 2001; Levesque, 2011; Nasir \& Tahir, 2012), their difficulties with communication (Simpson \& Myles, 1998), and from coping with a range of often co-occurring challenges such as sleep problems and sensory abnormalities (Mazurek et al., 2013). Aggressive behaviour can also limit access to treatment and impede social opportunities and involvement in everyday activities for both the individual and their family (Hodgetts et al., 2013). Additionally, the implications for family members of adolescents with ASD who display physical aggression are serious given the size and strength of these individuals (Mazurek et al., 2013).

\section{Strengths and limitations}

A primary strength of this study was the use of a PCT framework. The PCT perspective offered a detailed and helpful view for understanding a range of issues experienced by the adolescents with ASD and their families. The use of a qualitative methodology is also a strength of this study, as there is currently a dearth of literature incorporating the direct perspectives of individuals with ASD and their families (Carrington, Templeton, \& Papinczak, 2003; Cridland, Jones, Magee, \& Caputi, 2014; Fong, Wilgosh, \& Sobsey, 1993; Vliem, 2009).

However, it is necessary to interpret the findings with caution due to the relatively small and specific sample, as the findings may not be representative of all adolescents with ASD. The results nevertheless may be reflective of other adolescents' experiences, especially as the issues discussed were largely consistent with the available literature. Further, these preliminary findings may be useful for informing further research and clinical interventions. For example, the nature of identity development in adolescents with ASD, and the most suitable method of investigating this issue, remains unclear. Further research is recommended to investigate these and other issues raised in this study.

\section{Clinical recommendations}

This investigation raises the need to address a range of social, emotional, cognitive, and physical issues faced by adolescents with ASD. The following points outline recommendations for parents, clinicians, and teachers:

(1) Interviews indicated that many of the adolescents would benefit from more information about ASD. Information may have been provided to these individuals as children; however, given the range of new issues faced 
by adolescents, it is necessary to provide them with age-specific information. There are a range of resources targeted at this age group (e.g., books, DVDs, websites, chatrooms, and blogs) from which adolescents with ASD and their families may benefit.

(2) Providing adolescents with developmentally appropriate information about puberty is recommended (Chan \& John, 2012; Sullivan \& Caterino, 2008). The most efficacious strategies are likely to be those provided collaboratively between parents, clinicians, and teachers (Klett \& Turan, 2012; Nichols \& Blakeley-Smith, 2009; Travers \& Tincani, 2010). Critical information about puberty includes age-specific physical and emotional changes, healthy strategies for expressing emotions and sexuality, and socially appropriate versus inappropriate behaviour (as well as the rationale underlying these social "rules;" Klett \& Turan, 2012; Tarnai \& Wolfe, 2008). The context for puberty education should also be considered, as some of the adolescents conveyed embarrassment about learning about puberty within a general class environment.

(3) Clinical support is generally recommended for all individuals with ASD; however, it may be especially important for adolescents and their families, given the range of challenges inherent to this period (Carrington et al., 2003; McGorry, 2007; Stoddart, 1999). Crucial elements of clinical support include understanding the adolescent's worldview, facilitating awareness of the impact of oneself on others, issues of identity development, and managing day-to-day challenges (Cottenceau et al., 2012; McGorry, 2007; Stoddart, 1999).

(4) Monitoring, and where necessary intervention, for mental health issues is also imperative for adolescents with ASD (Kim, Szatmari, Bryson, Streiner, \& Wilson, 2000). Early warning signs for anxious or depressive symptomology in adolescents with ASD may include disorganisation, inattentiveness, decreased stress threshold, fatigue, and disinterest in hobbies and pleasurable activities (Carrington \& Graham, 2001).

(5) The influence of the school environment on the wellbeing of adolescents with ASD must not be underestimated. Strategies to promote a positive high school experience for adolescents with ASD may include the following:
- Staged transition from primary to high school with multiple orientation events and activities (Adreon \& Stella, 2001).

- Ongoing meetings between teachers and the family to ensure a collaborative approach to learning (Brewin, Renwick, \& Fudge Schormans, 2008).

- Teachers who have a general understanding of ASD and how it affects learning, as well as a detailed understanding about individual students with ASD and their unique sensitivities and interests.

- Suitable classroom support such as preferential seating arrangements, individualised learning plans, and assistance for assignments and exams (Adreon \& Stella, 2001).

- Peer education and coaching programs for increasing peer acceptance and understanding about ASD (Chan et al., 2009; Cridland, Jones, Caputi, \& Magee, 2014; Humphrey, 2008; Humphrey \& Symes, 2010).

(6) The present findings indicate that the adolescents' minimal involvement in social activities with peers did not equate to a lack of interest. Families would benefit from facilitating social interactions with both NTD and ASD peers, as both groups satisfy different social needs, including exposure to normative social interactions and the need to feel a sense of belonging (Bauminger et al., 2003). Interaction with peers is also important for identity development (Bauminger, Shulman, \& Agam, 2004). Additionally, families, clinicians, and teachers should be wary of focusing discussions with adolescents on the difficulties they may have in making friends, as the adolescents may internalise such statements and limit their attempts to develop friendships (Lasgaard et al., 2010).

\section{Conclusion}

The present study provides preliminary empirical support for the application of PCT for understanding adolescents with ASD. More specifically, findings indicated that PCT can provide an eloquent and empathetic approach for understanding a range of issues for adolescents with ASD, including interacting in the complex adolescent social realm, sense-making of multifaceted situations, identity development, development of flexible processing styles, and understanding and managing physical and emotional changes associated with puberty. Further research 
investigating the application of PCT for understanding adolescents with ASD is warranted in order to increase our understanding of ASD in general and provide these individuals, and their families, with appropriate support.

\section{Notes}

1. All participants with ASD were formally diagnosed with Asperger's syndrome (AS), which, according to the DSM-IV (APA, 2000), is a high-functioning form of ASD. The term ASD rather than $A S$ is used throughout the paper in order to be consistent with the DSM-5 (APA, 2013). However, terms associated with AS (e.g., Asperger's, Aspie) have been retained in direct quotations from participants in order to accurately portray their comments.

2. The NTD individuals could be either male or female.

3. From here on, the male adolescent participants with ASD will be referred to as "adolescents" and the NTD adolescent siblings as "siblings" or "brother" or "sister."

4. All names that appear in direct quotations have been changed to preserve the anonymity of participants.

\section{References}

Adreon, D., \& Stella, J. (2001). Transition to middle and high school: Increasing the success of students with Asperger syndrome. Intervention in School and Clinic, 36, 266-271. doi:10. 1177/105345120103600502

American Psychiatric Association. (2000). Diagnostic and statistical manual of mental disorders (4th ed., text rev.). Washington, DC: Author.

American Psychiatric Association. (2013). Diagnostic and statistical manual of mental disorders (5th ed.). Arlington, VA: Author.

Artar, M. (2007). Adolescent egocentrism and theory of mind: In the context of family relations. Social Behavior and Personality: An International Journal, 35, 1211-1220. doi:10.2224/sbp. 2007.35.9.1211

Badzinski, S. I., \& Anderson, J. A. (2012). An exploration of the identification of implicative dilemmas and their relationship to personal construct theory-congruent measures of psychological well-being in nonclinical samples. Journal of Constructivist Psychology, 25, 1-33. doi:10.1080/10720537. 2011.629111

Barnhill, G. P., \& Myles, B. S. (2001). Attributional style and depression in adolescents with Asperger syndrome. Journal of Positive Behavior Interventions, 3, 175-182. doi:10.1177/ 109830070100300305

Bauminger, N., Shulman, C., \& Agam, G. (2003). Peer interaction and loneliness in high-functioning children with autism. Journal of Autism and Developmental Disorders, 33, 489-507. doi:10.1023/A:1025827427901

Bauminger, N., Shulman, C., \& Agam, G. (2004). The link between perceptions of self and of social relationships in high-functioning children with autism. Journal of Developmental and Physical Disabilities, 16, 193-214. doi:10. 1023/B:JODD.0000026616.24896.c8

Benderix, Y., \& Sivberg, B. (2007). Siblings' experiences of having a brother or sister with autism and mental retardation: A case study of 14 siblings from five families. Journal of Pediatric Nursing, 22, 410-418. doi:10.1016/j.pedn.2007.08.013

Braun, V., \& Clarke, V. (2006). Using thematic analysis in psychology. Qualitative Research in Psychology, 3, 77-101. doi:10.1191/ 1478088706qp063oa

Brewin, B. J., Renwick, R., \& Fudge Schormans, A. (2008). Parental perspectives of the quality of life in school environments for children with Asperger syndrome. Focus on Autism and Other Developmental Disabilities, 23, 242-252. doi:10. 1177/1088357608322997

Butler, R. J. (2006). Investigating the content of core constructs. Personal Construct Theory \& Practice, 3, 27-33.

Card, N. A., Stucky, B. D., Sawalani, G. M., \& Little, T. D. (2008). Direct and indirect aggression during childhood and adolescence: A meta-analytic review of gender differences, intercorrelations, and relations to maladjustment. Child Development, 79, 1185-1229. doi:10.1111/j.1467-8624.2008.01184.x

Carrington, S., \& Graham, L. (2001). Perceptions of school by two teenage boys with Asperger syndrome and their mothers: A qualitative study. Autism, 5, 37-48. doi:10.1177/ 1362361301005001004

Carrington, S., Templeton, E., \& Papinczak, T. (2003). Adolescents with Asperger syndrome and perceptions of friendships. Focus on Autism and Other Developmental Disabilities, 18, 211-218. doi:10.1177/10883576030180040201

Chan, J., \& John, R. M. (2012). Sexuality and sexual health in children and adolescents with autism. The Journal for Nurse Practitioners, 8, 306-315. doi:10.1016/j.nurpra.2012.01.020

Chan, J. M., Lang, R., Rispoli, M., O'Reilly, M., Sigafoos, J., \& Cole, H. (2009). Use of peer-mediated interventions in the treatment of autism spectrum disorders: A systematic review. Research in Autism Spectrum Disorders, 3, 876-889. doi:10. 1016/j.rasd.2009.04.003

Cottenceau, H., Roux, S., Blanc, R., Lenoir, P., Bonnet-Brilhault, F., \& Barthélémy, C. (2012). Quality of life of adolescents with autism spectrum disorders: Comparison to adolescents with diabetes. European Child \& Adolescent Psychiatry, 21, 289296. doi:10.1007/s00787-012-0263-z

Cridland, E. K., Caputi, P., Jones, S. C., \& Magee, C. A. (2014) Understanding high-functioning autism during adolescence: A personal construct theory approach. Journal of Intellectual \& Developmental Disability, 39, 108-118. doi:10.3109/13668250. 2013.870331

Cridland, E. K., Jones, S. C., Caputi, P., \& Magee, C. A. (2014). Being a girl in a boys' world: Investigating the experiences of girls with autism spectrum disorders during adolescence. Journal of Autism and Developmental Disorders, 44, 1261-1274. doi:10.1007/s10803-013-1985-6

Cridland, E. K., Jones, S. C., Caputi, P., \& Magee, C. A. (2015). Qualitative research with families living with autism spectrum disorders: Recommendations for conducting semi-structured interviews. Journal of Intellectual \& Developmental Disability, 40, 78-91. doi:10.3109/13668250.2014.964191

Cridland, E. K., Jones, S. C., Magee, C. A., \& Caputi, P. (2014). Family-focused autism spectrum disorder research: A review of the utility of family systems approaches. Autism, 18, 213-222. doi:10.1177/1362361312472261

Farran, E. K., Branson, A., \& King, B. J. (2011). Visual search for basic emotional expressions in autism; impaired processing of anger, fear and sadness, but a typical happy face advantage. 
Research in Autism Spectrum Disorders, 5, 455-462. doi:10.1016/ j.rasd.2010.06.009

Fong, L., Wilgosh, L., \& Sobsey, D. (1993). The experience of parenting an adolescent with autism. International Journal of Disability, Development and Education, 40, 105-113. doi:10. 1080/0156655930400204

Fullerton, A., \& Coyne, P. (1999). Developing skills and concepts for self-determination in young adults with autism. Focus on Autism and Other Developmental Disabilities, 14, 42-52. doi:10. 1177/108835769901400106

Hodgetts, S., Nicholas, D., \& Zwaigenbaum, L. (2013). Home sweet home? Families' experiences with aggression in children with autism spectrum disorders. Focus on Autism and Other Developmental Disabilities, 28, 166-174. doi:10.1177/ 1088357612472932

Holtmann, M., Bölte, S., \& Poustka, F. (2007). Autism spectrum disorders: Sex differences in autistic behaviour domains and coexisting psychopathology. Developmental Medicine \& Child Neurology, 49, 361-366. doi:10.1111/j.1469-8749.2007. 00361.x

Howard, B., Cohn, E., \& Orsmond, G. I. (2006). Understanding and negotiating friendships: Perspectives from an adolescent with Asperger syndrome. Autism, 10, 619-627. doi:10.1177/ 1362361306068508

Hsiao, M.-N., Tseng, W.-L., Huang, H.-Y., \& Gau, S. S.-F. (2013). Effects of autistic traits on social and school adjustment in children and adolescents: The moderating roles of age and gender. Research in Developmental Disabilities, 34, 254-265. doi:10.1016/j.ridd.2012.08.001

Humphrey, N. (2008). Including pupils with autistic spectrum disorders in mainstream schools. Support for Learning, 23, 41-47. doi:10.1111/j.1467-9604.2007.00367.x

Humphrey, N., \& Symes, W. (2010). Responses to bullying and use of social support among pupils with autism spectrum disorders (ASDs) in mainstream schools: A qualitative study. Journal of Research in Special Educational Needs, 10, 82-90. doi:10.1111/j.1471-3802.2010.01146.x

Isomura, T., Ogawa, S., Yamada, S., Shibasaki, M., \& Masataka, N. (2014). Preliminary evidence that different mechanisms underlie the anger superiority effect in children with and without autism spectrum disorders. Frontiers in Psychology, 5, 1-8. doi:10.3389/fpsyg.2014.00461

Kanne, S. M., \& Mazurek, M. O. (2011). Aggression in children and adolescents with ASD: Prevalence and risk factors. Journal of Autism and Developmental Disorders, 41, 926-937. doi:10.1007/s10803-010-1118-4

Kelly, G. A. (1955). A theory of personality: The psychology of personal constructs (Vol. 1 and 2). New York, NY: Routledge.

Kelly, G. A. (2003). A brief introduction to personal construct theory. In F. Fransella (Ed.), International handbook of personal construct psychology (pp. 3-20). Chichester, England: Wiley.

Kim, J. A., Szatmari, P., Bryson, S. E., Streiner, D. L., \& Wilson, F. J. (2000). The prevalence of anxiety and mood problems among children with autism and Asperger syndrome. Autism, 4, 117-132. doi:10.1177/1362361300004002002.

Klett, L. S., \& Turan, Y. (2012). Generalized effects of Social Stories with task analysis for teaching menstrual care to three young girls with autism. Sexuality and Disability, 30, 319-336. doi:10.1007/s11195-011-9244-2

Koning, C., \& Magill-Evans, J. (2001). Social and language skills in adolescent boys with Asperger syndrome. Autism, 5, 2336. doi:10.1177/1362361301005001003

Krahn, T. M., \& Fenton, A. (2012). The extreme male brain theory of autism and the potential adverse effects for boys and girls with autism. Bioethical Inquiry, 9, 93-103. doi:10. 1007/s11673-011-9350-y

Kring, S. R., Greenberg, J. S., \& Seltzer, M. M. (2009). The impact of health problems on behavior problems in adolescents and adults with autism spectrum disorders: Implications for maternal burden. Social Work in Mental Health, 8, 54-71. doi:10.1080/15332980902932441

Lasgaard, M., Nielsen, A., Eriksen, M. E., \& Goossens, L. (2010). Loneliness and social support in adolescent boys with autism spectrum disorders. Journal of Autism and Developmental Disorders, 40, 218-226. doi:10.1007/s10803-009-0851-z

Levesque, R. J. R. (Ed.). (2011). Encyclopedia of adolescence. New York, NY: Springer Reference. doi:10.1007/978-14419-1695-2

Levy, A., \& Perry, A. (2011). Outcomes in adolescents and adults with autism: A review of the literature. Research in Autism Spectrum Disorders, 5, 1271-1282. doi:10.1016/j.rasd.2011.01. 023

Mascha, K., \& Boucher, J. (2006). Preliminary investigation of a qualitative method of examining siblings' experiences of living with a child with ASD. British Journal of Developmental Disabilities, 52(102), 19-28. doi:10.1179/096979506799103659

Mazurek, M. O., Kanne, S. M., \& Wodka, E. L. (2013). Physical aggression in children and adolescents with autism spectrum disorders. Research in Autism Spectrum Disorders, 7, 455-465. doi:10.1016/j.rasd.2012.11.004

McCoy, M. M. (1977). A reconstruction of emotion. In D. Bannister (Ed.), New perspectives in personal construct theory (pp. 93-124). New York, NY: Academic Press.

McGorry, P. D. (2007). The specialist youth mental health model: Strengthening the weakest link in the public mental health system. The Medical Journal of Australia,187, S53-S56.

McGovern, C. W., \& Sigman, M. (2005). Continuity and change from early childhood to adolescence in autism. The Journal of Child Psychology and Psychiatry, 46, 401-408. doi:10.1111/j. 1469-7610.2004.00361.x

McGuire, J. E. (2009). A strengths-based approach to building social competence in adolescents with Asperger's syndrome (Doctoral dissertation). Alliant International University, CA.

Müller, E., Schuler, A., \& Yates, G. B. (2008). Social challenges and supports from the perspective of individuals with Asperger syndrome and other autism spectrum disabilities. Autism, 12, 173-190. doi:10.1177/1362361307086664

Myles, B. S., \& Simpson, R. L. (2003). Asperger syndrome: A guide for educators and parents (2nd ed.). Austin, TX: Pro-Ed.

Nasir, S. J., \& Tahir, S. (2012). Anger, anxiety and depression in children with autism in home and school settings: A qualitative analysis. Journal of Behavioural Sciences, 22(2), 83-98.

Nichols, S., \& Blakeley-Smith, A. (2009). "I'm not sure were ready for this ...": Working with families toward facilitating healthy sexuality for individuals with autism spectrum disorders. Social Work in Mental Health, 8, 72-91. doi:10.1080/ 15332980902932383

Orsmond, G. I., \& Kuo, H.-Y. (2011). The daily lives of adolescents with an autism spectrum disorder: Discretionary time use and activity partners. Autism, 15, 579-599. doi:10.1177/ 1362361310386503

Pakenham, K. I., Sofronoff, K., \& Samios, C. (2004). Finding meaning in parenting a child with Asperger syndrome: Correlates of sense making and benefit finding. Research in Developmental Disabilities, 25, 245-264. doi:10.1016/j.ridd. 2003.06.003

Pelphrey, K. A., Sasson, N. J., Reznick, J.S., Paul, G., Goldman, B. D., \& Piven, J. (2002). Visual scanning of faces in autism. 
Journal of Autism and Developmental Disorders, 32, 249-261. doi:10.1023/A:1016374617369

Pinkerton, J., \& Dolan, P. (2007). Family support, social capital, resilience and adolescent coping. Child \& Family Social Work, 12, 219-228. doi:10.1111/j.1365-2206.2007.00497.x

Poon, K. K., Soon, S., Wong, M.-E., Kaur, S., Khaw, J., Ng, Z., \& Tan, C. S. (2014). What is school like? Perspectives of Singaporean youth with high-functioning autism spectrum disorders. International Journal of Inclusive Education, 18, 10691081. doi:10.1080/13603116.2012.693401

Procter, H. G. (2001). Personal construct psychology and autism. Journal of Constructivist Psychology, 14, 107-126. doi:10.1080/ 10720530125885

QSR International. (2012). NVivo 10 (Version 10) [Computer software]. Doncaster, Australia QSR International Pty Ltd.

Rowe, D. (2003). Personal construct psychology and me. In F. Fransella (Ed.), International handbook of personal construct psychology (pp. 397-404). Chichester, England: Wiley. doi:10. 1002/0470013370.ch40

Schuntermann, P. (2007). The sibling experience: Growing up with a child who has pervasive developmental disorder or mental retardation. Harvard Review of Psychiatry, 15, 93-108. doi:10.1080/10673220701432188

Seltzer, M. M., Shattuck, P., Abbeduto, L., \& Greenberg, J. S. (2004). Trajectory of development in adolescents and adults with autism. Mental Retardation and Developmental Disabilities Research Reviews, 10, 234-247. doi:10.1002/mrdd.20038

Simpson, R. L., \& Myles, B. S. (1998). Aggression among children and youth who have Asperger's syndrome: A different population requiring different strategies. Preventing School Failure: Alternative Education for Children and Youth, 42, 149-153. doi:10.1080/10459889809603730

Smith, L. E., Maenner, M. J., \& Seltzer, M. M. (2012). Developmental trajectories in adolescents and adults with autism: The case of daily living skills. Journal of the American Academy of Child and Adolescent Psychiatry, 51, 622-631. doi:10.1016/j.jaac.2012.03.001
Stoddart, K. P. (1999). Adolescents with Asperger syndrome: Three Case studies of individual and family therapy. Autism, 3, 255-271. doi:10.1177/1362361399003003004

Sullivan, A., \& Caterino, L. C. (2008). Addressing the sexuality and sex education of individuals with autism spectrum disorders. Education \& Treatment of Children, 31, 381-394. doi:10.1353/etc.0.0001

Tarnai, B., \& Wolfe, P. S. (2008). Social Stories for sexuality education for persons with autism/pervasive developmental disorder. Sexuality and Disability, 26, 29-36. doi:10.1007/ s11195-007-9067-3

Travers, J., \& Tincani, M. (2010). Sexuality education for individuals with autism spectrum disorders: Critical issues and decision making guidelines. Education and Training in Autism and Developmental Disabilities, 45, 284-293.

Truneckova, D., \& Viney, L. L. (2012). Personal construct psychology model of school counselling delivery. British Journal of Guidance \& Counselling, 40, 431-448. doi:10.1080/ 03069885.2012.718739

Vliem, S. J. (2009). Adolescent coping and family functioning in the family of a child with autism (Doctoral dissertation). The University of Michigan.

Walker, B. M. (1996). A psychology for adventurers: An introduction to personal construct psychology from a social perspective. In D. Kalekin-Fishman \& B. M. Walker (Eds.), The construction of group realities: Culture, society, and personal construct theory (pp. 7-29). Malabar, FL: Krieger.

White, S. W., \& Roberson-Nay, R. (2009). Anxiety, social deficits, and loneliness in youth with autism spectrum disorders. Journal of Autism and Developmental Disorders, 39, 1006-1013. doi:10. 1007/s10803-009-0713-8

Willey, L. H. (Ed.). (2003). Asperger syndrome in adolescence: Living with the ups, the downs and things in between. London, UK: Kingsley.

Ybrandt, H. (2008). The relation between self-concept and social functioning in adolescence. Journal of Adolescence, 31, 1-16. doi:10.1016/j.adolescence.2007.03.004 